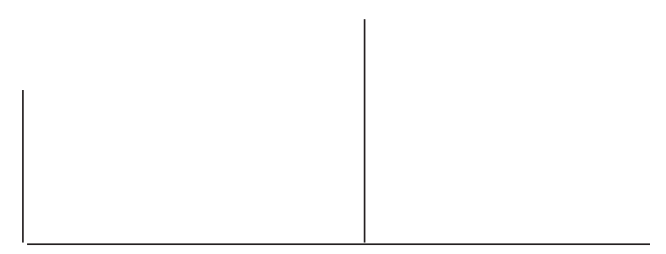

Rev. Latinoam. Psicopat. Fund., IX, 3, 484-495

\title{
O paradoxo do diagnóstico precoce de câncer*
}

\author{
Cristina Lindenmeyer-Saint Martin
}

\begin{abstract}
Como circunscrever o discurso do paciente que teve diagnóstico de câncer com técnicas de deteç̧ão precoce dessa doença?

A partir de dois casos clínicos, tentamos desenvolver a idéia de um efeito traumático no paciente ao ser informado desta doença potencialmente mortal. Assistimos à recomposiçao do fantasma de morte com o enunciado do discurso médico, figura reduplicada dos pais não protetores. E o corpo constitui-se como um objeto "fobogênico", lugar de projeção do traumático. Desta forma o sujeito instala-se numa posição de identificação ao agressor segundo os termos de Ferenczi.

Durante o tempo em que o paciente se mantiver numa posição exterior em relação ao seu corpo libidinal - e será isto que facilitará o discurso médico - ele ficará hipnotizado pelo agressor, repetindo desta forma um comportamento infantil, de submissão aos maus pais. Despossuídos de seus próprios corpos, esses pacientes testemunham dos destinos pulsionais mais variáveis, chegando a formas mais mórbidas.
\end{abstract}

Palavras-chave: Câncer, fantasma, identificação ao agressor, morbidez

* Este texto é o resultado de meu trabalho de elaboraçao a partir dos comentários propostos pela profa. C. Rigaud e minha tese de Doutorado sob a orientação de Pierre Fédida.

Este trabalho foi apresentado no I Congresso Internacional de Psicopatologia Fundamental e VII Congresso Brasileiro de Psicopatologia Fundamental, na PUC-RJ, setembro de 2004. 
Uma das características do câncer, segundo o discurso da medicina moderna, é poder se desenvolver em silêncio, sem que o sujeito, ao menos nas primeiras fases da doença, o sinta de forma dolorosa.

As técnicas atuais, particularmente desenvolvidas em hospitais especializados, permitem aos médicos detectar o desenvolvimento dessa doença graças às diversas investigações no corpo do sujeito e antes mesmo que este tenha percebido qualquer modificação em seu próprio corpo. Essas técnicas são tão sofisticadas que dão aos médicos a possibilidade de aceder aos lugares reconhecidos como os mais profundos do corpo humano, a sua organização celular.

É então o saber médico que inaugura a presença da doença e identifica o paciente com seus aspectos mórbidos, sem que este tenha percebido qualquer sensação corporal que possa indicar que algo se passe com ele. Ou seja, é a intervenção do saber médico que desenvolve no sujeito o reconhecimento de que ele tem uma doença grave e que se encontra ameaçado de morte.

Quer dizer que a situação de doença vivida por nossos pacientes não aparece como efeito de um trauma que já aconteceu, mas como tendo um efeito traumático.

O efeito traumático do anúncio da doença potencialmente mortal provoca uma certa percepção corporal a partir da qual uma ruptura se estabelece, ou é reforçada, entre o sujeito e seu próprio corpo, fazendo aparecer uma multiplicação de sintomas. Assistimos então a recomposiçao no sujeito de seu fantasma de morte com o anúncio da doença feito pelo médico. Esta recomposição define as condições necessárias para reatualização de um fantasma já vivido pelo sujeito em seu passado.

$\mathrm{O}$ que nos interessa aqui é analisar como esse passado vem se colar ao anúncio da doença verbalizada pelo médico, figura reduplicada dos pais não protetores.

Pela nossa prática com esses pacientes, a partir desse momento o corpo se constituiria como um objeto fobogênico, lugar de projeção do traumático devido ao discurso médico que anuncia a presença da doença (cf. Lindenmeyer, 2005). 


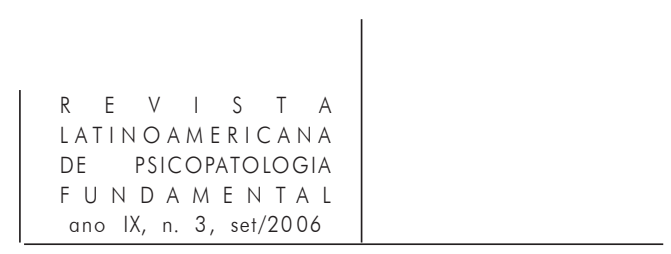

O efeito traumático desta étrangéreté do corpo parece continuar através de uma retomada ativa do traumatismo: alguma coisa parece ser controlada sob a forma de uma teorização - como vemos nas teorias sexuais infantis - localizando o mal-estar do corpo em uma entidade que do exterior poderia levar a esse estado de sofrimento.

Esse exterior, representado pela doença, pode ser assimilado ao passado do sujeito que se sente parcialmente despossuído devido à onipotência das instâncias parentais, que possuem um lugar preponderante. Podemos falar desta retomada de sua história sob a forma de um "romance", como foi proposto por M. José del Volgo (1993, p. 63-77), mais próximo de uma narração do que de um verdadeiro processo de subjetivação.

Analisaremos agora, pela narração de dois casos clínicos, como o discurso médico pode reatualizar o efeito traumático do pavor no qual se cola o anúncio da doença, e, num segundo momento, a tentativa, por parte do paciente, de dar uma coerência ao estado de doença, ligando-a aos elementos de seu passado.

\section{Casos clínicos}

A necessidade de recorrer à história pessoal em que os pais detêm um lugar preponderante nos envia, num primeiro tempo, a uma leitura direta dos sintomas ligados a um mal-estar psíquico bem mais do que um verdadeiro processo de introjeção, o que ocorreria num segundo momento.

Este movimento de introjeção só poderá ocorrer após um trabalho sobre o silêncio do paciente, produzindo uma verdadeira reelaboração do passado e não uma espécie de mágica visando uma ação sobre o passado. A confrontação com o traumático causado pela doença ficaria desta forma evitada neste acting.

Esta causalidade nos leva ao que Roland Gori (1993) chama de "determinismo mágico”: “... estes pacientes ligam não sem pertinência, com a permissão da psicanálise, certos sintomas somáticos às suas histórias singulares... Além das explicações psicológicas, esses sintomas vêm a ser o lugar de reminiscências, devido ao fato de não acharem um determinismo transferencial e associativo que dariam seus verdadeiros valores. Ainda aí, a construção prevalece sobre a interpretação por uma leitura direta da coincidência dos sintomas e lembranças. Faltaria o essencial, a validade pelo e na transferência desta teoria dinâmica”.

No caso da sra. D., as figuras dos pais serão lembradas no contexto do sofrimento psíquico infligido devido ao anúncio do resultado negativo do tratamento médico. 


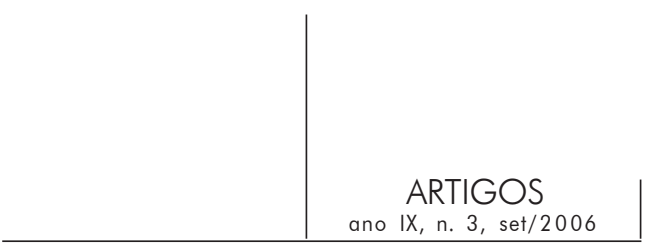

A paciente, sra. D., é uma mulher de 52 anos, secretária. Faz quatro anos que ela está em tratamento quimioterápico para curar-se de um carcinoma no ovário. Ela decide começar uma psicoterapia devido a insistência de seu médico oncologista.

Encontro a sra. D. durante uma de suas hospitalizações.

Segundo as informações de seu médico a paciente sofreu, no ano que seguiu ao seu diagnóstico de câncer, uma intervenção que, segundo ele, normalmente deveria ser suficiente para acabar com a doença. No entanto, esta reaparece um ano mais tarde. Inicia-se então um tratamento quimioterápico.

Esta seqüência será repetida mais uma vez dando em novo resultado negativo. Assim acaba, para a sra. D., toda esperança de cura.

Durante os dois anos seguintes ela será hospitalizada por várias vezes para operação, tratamento quimioterápico e radiações, sem que essas intervenções impeçam a doença de progredir.

Durante uma seção que se passou no primeiro ano de nosso trabalho terapêutico a sra. D. diz o seguinte: Eu estou completamente desmotivada hoje. Eu fiz tudo o que precisava. Os médicos me diziam que eu ficaria curada. Eles se enganaram. Agora eu não tenho mais nada dentro de mim, eles me retiraram tudo de dentro. Eu não tenho mais nada.

A sra. D. continua a nos dizer como, durante toda a sua vida, era ela quem controlava tudo, em toda parte. Segundo ela sempre foi assim desde que era pequena o que vem explicar o fato de ter que construir para ela uma vida independente dos outros da minha família.

Neste momento não podemos nos impedir de associar com o fato de que atualmente a sra. D. vive sua doença sozinha, sem contato com sua irmã ou irmão e mesmo chegando a proibir a visita de seu marido ou filhos ao hospital.

Ela continua: Eu nunca me entendi bem com a minha irmã ou com o meu irmão, assim como com a minha mãe. Com o meu pai eu me entendia bem, mesmo muito bem. A gente não se falava muito, mas nos compreendíamos. Ele não era mau, somente quando ele chegava em casa cambaleando é que tudo começava.

Após alguns instantes de hesitação, ela continua: Cada vez que ele chegava em casa desse jeito, minha mãe e minha irmã começavam a chateá-lo. E como ele não suportava isto, começava a quebrar tudo e a bater nelas... Comigo não acontecia nada. Eu ia para um canto e tentava não incomodá-lo. Eu via tudo isso, mas ficava ali sozinha no meu canto sem me mexer.

Nesta reivindicação de se mostrar como forte e capaz de tudo suportar, a sra. D. nos faz entender o grito de desespero de quem, face à violência paterna, só havia uma solução: ficar só sem se mexer. Agora, face à sua doença, vivida como violência, esse mesmo movimento se repete. Sentimento de abandono que 


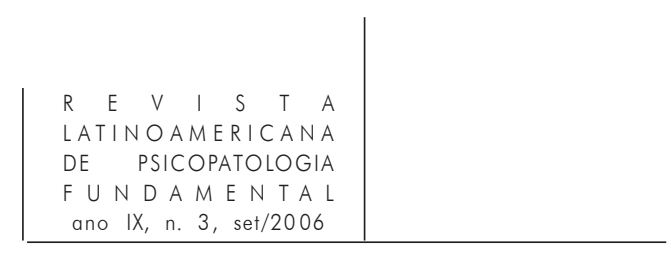

já existia na relação com seus pais: mãe ausente nos cuidados maternos e autoritária, e alcoolismo do pai, este insuficiente no seu papel de proteção.

Ela continua: Já faz mais ou menos cinco ou seis anos que ele morreu. Eu não me lembro muito bem, mas é mais ou menos isto. Sem dar mais precisão sobre a data da morte de seu pai, ela acrescenta que ele morreu de um câncer na garganta: Ele fumava muito e acabou tendo um câncer na garganta. Ele fez uma primeira operação e os médicos pensavam que era suficiente, que após ele ficaria curado. Um ano mais tarde, ele estava com um câncer no pulmão. Já era tarde demais para fazer algo e ele morreu.

A sua própria morte, ressentida nas várias mutilações que ela sofreu no seu próprio corpo, são rapidamente associadas à doença de seu pai que os médicos não conseguiram curar. De certa forma, a sra. D. repete no seu próprio corpo o sofrimento corporal vivido por seu pai. Ele morreu de uma forma horrível. [Pausa] Era um câncer.

Ao longo dessa narração, a sra. D. parece se colocar numa identificação ao pai onde se instalou uma comunicação maldita ou mau dita, onde seu próprio corpo vem a ser o lugar da cena onde podiam se exprimir suas experiências vividas no passado. Lugar de teatralização - segundo J. McDougall - necessário para uma compreensão no presente de sua história.

A evocação da doença do pai parece vir confirmar este tipo de identificação, vivido no mal-estar. E de certa forma esta ligação na fatalidade mortífera persiste através de seu corpo. Corpo vivido como "sofredor", como lembra R. Gori. Para a sra. D. a morbidez da relação com os pais se repercute no corpo, como uma máquina em que os mecanismos parecem estar em comunicação direta com o que representam os comportamentos e intenções dos pais através dos impulsos dados à máquina por meio das palavras ditas no passado (Aqui as disputas entre os pais).

Através de um outro caso clínico, compreendemos os efeitos da identificação do paciente com o discurso médico e com o tratamento no qual esta paciente foi sujeita. Esta breve ilustração clínica nos permitirá compreender por que o recurso aos elementos do passado, vividos como onipotentes, numa continuidade com o mal-estar psíquico produzido pela presença da doença, é uma tentativa de ultrapassar essa sensação de exterioridade do corpo, provocada pelo discurso médico sobre esse mesmo corpo.

O primeiro encontro com Lory aconteceu no hospital, quando ela estava começando seu terceiro tratamento quimioterápico para tratar de seu câncer nos intestinos.

Desde este primeiro encontro com Lory, ela dará múltiplas explicações objetivas de seus problemas corporais. Pelas poucas palavras lançadas nos grandes momentos de silêncio, ela parece testemunhar sua "retenção" interna, parecendo traduzir um corpo que se representa para nós como carregado de con- 
teúdo, mas contraído. Nesses momentos Lory nos fala com um discurso ritualizado, carregado de retenção e contrariedade, que seu corpo nos obriga a escutar.

A sra. sabe, é muito difícil suportar. Quando eu penso que não acabou, que será necessário recomeçar tudo novamente.

Seu discurso, sempre cheio de retenção, me dava em certos momentos vontade de intervir e lhe pedir para desenvolver mais suas idéias.

Ela continua: O médico me dizia que eu tinha um tumor nos intestinos, e que após a operação tudo ficaria bem. Um ano mais tarde eu comecei a ter dores na barriga e eles me diziam que eu imaginava essas dores. Durante todo esse tempo eu suportei tudo isto. Ela continua: Eu acreditei nos médicos, pois sempre fui uma pessoa ansiosa, como meu pai e minha avó. [Pausa] Eu sempre fui mais próxima de meu pai do que de minha mãe. Minha mãe é uma pessoa rígida, ela nunca se ocupou de mim, era minha avó que me cuidava (avó paterna). Às vezes, eu detestava minha mãe, eu queria que ela morasse, mas nada acontecia com ela. A gente pensa isto quando a gente é pequena, né?

Lory nos apresenta sua mãe como sendo uma pessoa estrangeira a esta criança que não parava de reclamar da ausência de uma mãe de verdade. Quanto ao seu pai, morto de câncer alguns meses antes de ela descubrir o seu próprio, Lory sublinha toda a afeição que este lhe dava, sendo assim a única pessoa capaz de compreendê-la.

Era sempre ele que cuidava dos meus filhos. Após a sua morte eu me senti verdadeiramente só.

Ao falar de sua mãe Lory não a apresentava somente como rival, mesmo se no seu discurso podíamos perceber esse aspecto, mas como uma figura mais ameaçadora ainda. Ela evocava então lembranças de uma criança rejeitada e mal amada, como para nos provar seu sofrimento.

Hoje, minha mãe veio me ver. [Silêncio] Ela me disse: Quando tu não estás fazendo quimio, tu ficas bem. Parece não ter nada. Ela não entende porque eu estou no hospital. Por isto estou deprimida hoje. Para minha mãe, se eu não seguisse o tratamento eu estaria bem. Continuando a chorar, ela diz: Mas a sra. sabe o que acontece sem a quimio! Eu tenho um câncer, o que ela quer mais? Então desde quando ela veio aqui, eu tenho a impressão que nada está bem. Com o meu câncer é assim, eu sinto como se ele me devorasse no interior. Quando algo acontece comigo, eu posso esperar, ele dá sinal de vida. 


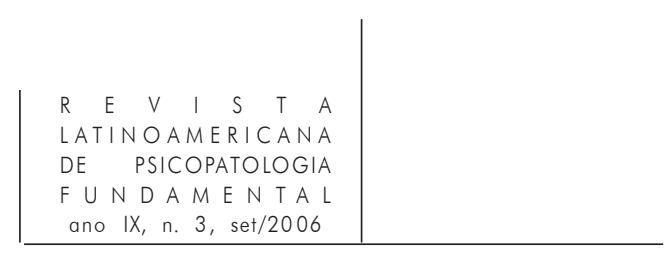

\section{O efeito hipnótico}

Estas poucas linhas sobre Lory nos levam a pensar sobre essa ligação particular com ao corpo no qual a doença transforma este último no estranho onipotente que o paciente gostaria de destruir.

Os desacordos dos pais, mantidos secretos ao longo da infância, tomam uma dimensão mortífera na criança que será sacrificada mais tarde pela doença: o câncer vem a ser a cena primitiva visível no corpo do descendente. Como se fosse necessário que algo no corpo do filho seja sacrificado por que seja dita a violência do pulsional familiar. Os estragos produzidos no corpo do sujeito permitem ilustrar esse isolamento vivido na infância, mas que ficou não-dito, até o aparecimento da doença. A doença vem a ser o despertador, sob o efeito do choque, de algo em si mesmo na espera do dizer. A realidade do sofrimento vivida por intermédio do corpo parece transformar a realidade presente (o câncer) reatualizando, sob a forma de uma ameaça de morte primitiva, impossível de suportar.

O anúncio do diagnóstico da doença vai estabelecer um corte entre um estado anterior de confiança em si, em que a capacidade de afrontar o mundo estava segura e um estado de desilusão após a perda da ilusão de que nada poderia acontecer de mortal. Esta desilusão vai se traduzir pela queixa freqüente desses pacientes: Eu nunca pensei que realmente um dia isto poderia acontecer comigo.

A partir disto, o que Lory projeta no seu corpo é a representação de um assassino, do seu assassino, ela se pensa condenada. E para satisfazer os desejos de sua mãe, ela tem como solução sua própria morte. Esta é a intensidade da cena primitiva violenta, seja sob a forma das agressões repetitivas dos pais e das passagens a atos brutais sob o efeito do álcool, seja da aliança destrutiva dos pais contra os filhos.

Ficamos surpresos na escuta clínica da presença onipotente de pais e de suas disputas seja entre eles, seja na relação destes com o paciente.

Esses momentos de violência não-ditos parecem estar à espera de um choque físico, de uma comoção que pode ser a doença para fazer ressurgir lembranças, restos diurnos que enfim serão evocados após a sensação de estranheza vivida através do corpo. E quando a doença chega, parecem aliviados, como se existisse a necessidade da utilização do sintoma orgânico. Como nos lembra Fédida (1992, p. 113-36) no seu texto “L’hipocondrique médecin” essas pessoas parecem estar a procura de uma doença como forma de negociação com uma angústia primitiva: através da doença essa angústia acharia um lugar de expressão.

Haveria, então, uma atitude extremamente defensiva contra o representável da morte, o que precipitaria o sujeito numa forma de compulsão última de 


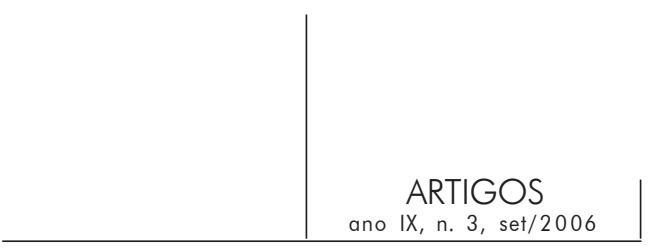

repetição, ou, ao contrário, uma atitude sem nenhuma resistência à morte (morte real, morte no real).

\section{O sedutor e o seduzido}

O efeito traumático do anúncio da doença vem do fato de que esse anúncio é feito pelo médico: este que detém a autoridade pelo saber. O médico é ao mesmo tempo o que anuncia a doença, mas propõe a cura.

Se pensarmos a sedução tal como foi defendida por Freud nas suas publicações de 1895 a 1896, a vítima é, na maior parte do tempo, a criança. O personagem sedutor é sempre um adulto no que caracteriza o ato principal da cena.

O que nos parece importante é insistir no estatuto de autoridade que o adulto pode exercer sobre a criança. A função dos adultos sendo a de estabelecer as regras nas condutas das crianças.

De acordo com o que pudemos observar nos nossos pacientes, estes se posicionam na relação com o médico, este último sendo o que anuncia a doença, mas que também propõe a cura através do tratamento quimioterápico, como um ser vulnerável, frágil como é uma criança. E mais, como uma criança seduzida: esta fragilidade a levaria, no fantasma, ao desarranjo pulsional onde se instalaria o sadismo do adulto sedutor. A característica da fragilidade, segundo os escritos de Freud, faz da vítima o seduzido. Os sentimentos descritos por esses pacientes parecem descrever essa mesma posição de submissão na relação com o médico. Assim dizia Lory, quando nos conta o que pensou quando esperava na sala de espera para sua primeira consulta: Estas pessoas, todas condenadas, não se falam, por economia das palavras. Era como se estivéssemos no vazio, um vazio que é a forma que se toma para escutar o que os patrões dos nossos corpos nos dizem. E a gente espera, o médico vai chegar. E, engraçado, eles se vestem de branco como se viessem nos falar das coisas do destino. Eles nos falam e é nas suas mãos que a gente se sente nesse momento.

Sabemos que para Ferenczi o que faz trauma no ato de sedução não é tanto o conteúdo do ato, mas a diferença de estatuto entre o sedutor (adulto) e o seduzido (a criança), sendo o adulto que emite as regras. A distância generacional alimenta então o poder do sedutor. A sedução da criança pelo adulto não teria o mesmo impacto patogênico que a exercida por duas crianças. O adulto tendo, para a criança, o conhecimento de tudo, em particular do bem e do mal.

Ferenczi insiste sobre este estado de desamparo da criança face ao adulto que impõe o ato. O tempo do pavor se situa no momento em que o adulto, que 


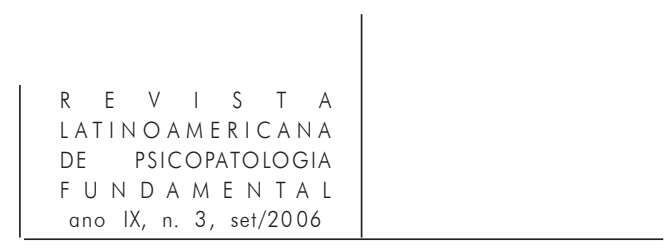

poderia funcionar como "pára-excitação", vem a ser "excitação", levando a criança a uma hemorragia de movimentos pulsionais sem retenção.

O que observamos em nossa clínica é que se organizaria uma percepção fantasmática em relação ao médico, onde neste último parece se localizar um pacto com a morte.

O médico ocuparia um espaço onde a intricação da libido e da pulsão de morte parecem se instalar através de momentos sádicos, ligados à mutilação do corpo e de sua decomposição.

No entanto, o médico pode, ele mesmo, sentir-se ultrapassado pelo poder da pulsão de morte. Seria o que ressentiria esses pacientes que recaem, perdendo assim confiança no holding estabelecido na relação com o médico. Instalar-seia então um jogo terrível entre o poder do médico e o poder da morte. No caso de recaída e recomeço de novo tratamento, a onipotência se localizaria ao lado da morte, figura que se confunde com o médico vivido como persecutor através do corpo, novamente castrado em uma nova parte desse mesmo corpo.

A sra. D. nos dizia: Agora eu não tenho mais nada, eles me retiraram tudo de dentro. Não tenho mais nada dentro de mim. Isto quando lhe foi retirado os ovários.

O ser e a identidade sexual são vividos numa perda simultânea, provocando uma ferida narcísica insuportável.

A ação do médico se associa à da morte, devorando o corpo mais e mais.

Esta dupla função o faz entrar na categoria dos maus pais: ao invés de ser "pára-excitação" devido ao seu papel de dar cuidados, passa a ser mau porque incapaz de parar os ataques da morte. O médico vem a ser o sedutor, pois ao mesmo tempo que anuncia a doença, propõe a cura. Mantém-se numa dimensão profética.

Detendo a verdade sobre o sujeito, mesmo antes que o sujeito sinta que algo se passa no seu corpo, ele desapropria esse mesmo sujeito de seu próprio corpo, de sua própria vida fantasmática.

O paciente não reconhece mais seu corpo, incapaz de prevenir do perigo existente. Assim se distanciaria através de um comportamento de evitação como podemos observar nos processos fóbicos: o corpo assusta como se fosse algo do estrangeiro, como o estrangeiro.

\section{Conclusão}

É somente quando as representações médicas são incapazes de ajudar o paciente a elaborar sua doença, que os médicos no-los enviam. 
O sujeito que passa a ser paciente, viveria numa posição de vítima infantil descrita por Ferenczi, aderindo de forma masoquista. Como podemos observar nos casos citados acima, o anúncio da doença entra em ressonância com as palavras dos pais no passado. Durante todo o tempo em que o paciente continuaria a se sentir exterior ao seu corpo libidinal, e será isto que facilitará o discurso médico, ele ficaria hipnotizado pelo agressor, repetindo assim o comportamento da criança de submissão aos pais maus. Tal seria a posição masoquista. Despossuídos de seus próprios corpos estes testemunham arranjos pulsionais mais diversos, chegando a formas mais mórbidas.

Assim falara Lory: Eu era uma criança difícil e minha avó me dizia sempre que eu iria sofrer muito na vida.

A palavra da avó (pessoa que se ocupava dela no lugar da mãe) funciona como palavra terrível e profética. O anúncio da doença pelo médico vem confirmar esta dimensão premonitória do enunciado pela avó.

E o que o trabalho analítico poderá reintroduzir, é precisamente esta dimensão traumática e angustiante que se impõe a eles, na ocasião da confrontação com a ameaça de morte que introduz o diagnóstico do câncer. Sua função seria a de introjetar estes elementos do passado, através do trabalho na transferência, ao invés de uma leitura direta do sintoma. O que sustentamos é a recusa de uma ilusão realista de uma reconstrução do passado no trabalho de historicização do trabalho analítico.

\section{Referências}

Canguilhem, G. Le normal et le pathologique. 5. éd. Paris: PUF, 1994.

Del Volgo, M. J. L’instant de dire. Cliniques méditerranéennes, Toulouse: Erès, n. 37/ 38, p. 63-77, 1993.

FÉDIDA, P. (1992). Crise et contre-transfert. L’hypocondriaque médecin. In: Monographie de la revue française de psychanalyse. L'hypocondrie. Paris: PUF, 1995. p. 113-36.

Ferenczi, S. (1933). Confusion de langue entre les adultes et l'enfant. Le langage de la tendresse et le langage de la passion. In: Euvres complètes. (art. posthumes). Paris: Payot, 1982. v. IV

Réflexions sur le traumatisme. In: Oeuvres complètes. Paris: Payot, 1982. v. IV.

Foucault, M. Naissance de la clinique. 3. éd. Paris: PUF, 1993.

Freud, S. (1915). Pulsions et destins de pulsions. In: EEuvres complètes. Paris: PUF, 1994. v. XIII. 


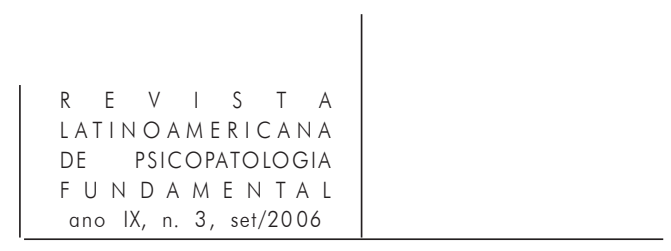

(1919-1920). Au-delà du principe de plaisir. In: Oeuvres complètes. Paris: PUF, 1996. v. XV.

(1925). Inhibition, symptôme et angoisse. In: Euvres complètes. Paris: PUF, 1992. v. XVII.

GoRI, R. La passion de la causalité: une parole en cause. Cliniques méditerranéennes, Toulouse: Erès, n. 37/38, p. 7-33, 1993.

Lindenmeyer-Saint Martin, C. Approche clinique psychanalytique de personnes soumises aux techniques de détections précoces du câncer. Paris: Presses Universitaires du Septriton, 2005.

Lispector, C. Uma aprendizagem ou o livro dos prazeres. Rio de Janeiro: Francisco Alves, 1990.

Masud R. Khan, M. Figures de la perversion. Paris: Gallimard, 1979.

McDougall, J. Thêatres du corps. Paris: Gallimard, 1989

Eros aux mille et un visage. Paris: Gallimard, 1996.

Winnicotr, D. W. Jeu et réalité. L’espace potentiel. Paris: Gallimard, 1975.

\section{Resumos}

Cómo puede circunscribirse el discurso de un paciente al que se le diagnosticó un cáncer gracias a técnicas de detección temprana?

A partir de dos casos clínicos, tratamos de desarrollar la idea de que un efecto traumático se produce en el/la paciente cuando es informado/a de la presencia de una enfermedad potencialmente mortal. Asistimos a la recomposición de la fantasía de muerte. El cuerpo se constituye como objeto "fobígeno", lugar proyectivo del trauma. De este modo, el/la sujeto se coloca en una posición de identificación con el agresor, según la terminología de Ferenczi.

En tanto y en cuanto el/la paciente permanezca en una posición exterior respecto de su cuerpo libidinal - y esto es exactamente lo que facilita el discurso médico - será hipnotizado/a por el agresor, repitiendo así un comportamiento infantil de sumisión a los padres. Al no estar en posesión de sus propios cuerpos, estos/as pacientes experimentan diversas vicisitudes pulsionales, reteniendo las más mórbidas.

Palabras claves: Cáncer, fantasma, identificación com el agresor, mórbidas

Comment circonscrire le discours du patient qui a eu diagnostic du câncer à partir des techniques précoces de cette maladie?

A partir de deux cas cliniques nous avons développé l'idée d'un effet traumatique chez le patient au moment où il reçoit l'annonce de la maladie potentiellement mortelle. 
Nous assistons alors à la recomposition de son fantasme de mort avec l'énoncé du discours médical, figure re-dupliquée des parents non protecteurs. Son corps se constitue comme objet "phobogène", lieu de projection du traumatique. De cette façon le sujet s'installe dans une position d'identification à l'agresseur selon les termes développés par Ferenczi.

Pendant tout le temps que le patient se maintiendra dans cette position extérieure par rapport à son propre corps libidinal, et ce será ce que facilitara le discours médical, il restera hypnotisé par l'agresseur, répétant ainsi un comportement infantile, de soumission aux mauvais parents. Dépourvu de ses propres corps ce patient témoigne des destins pulsionnels les plus variables, arrivant à des formes les plus morbides.

Mots clés: Cancer, fantasme, identification à l'agresseur, morbides

How can one circumscribe the discourse of a patient who has been diagnosed for câncer through early detection techniques?

Based on two clinical cases, the idea is discussed here of a traumatic effect on the patient upon being informed of the presence of a potentially mortal disease, in this case, cancer. One can observe the reconstruction of the death fantasy with the enunciation of the medical discourse, a return of the figure of non-protective parents. The body is constituted as a "phobogenic" object, that is the projective place of the trauma. The subject identifies with the aggressor, in a process like that described by Ferenczi.

As long as the patient remains in a position of outsider in relation to his/her libidinal body, medical discourse is facilited and the patient becomes hypnotized by the aggressor thus repeating infantile behavior of submission to the bad parents. Deprived of their own bodies, these patients may experience a variety of movements of the drives, and even morbid possibilities may arise.

Keys words: Cancer, fantasy, identification with the agressor, morbid 